\title{
From A Deficit-based to an Appreciative Inquiry Approach in Extension Programs: Constructing a Case for a Positive Shift in the Current Extension Intervention Paradigm DOI: $10.5191 /$ jiaee.2010.17305
}

\author{
Tsakani Ngomane \\ University of Pretoria, South Africa \\ Tsakani.Ngomane@up.ac.za
}

\begin{abstract}
This paper presents a philosophical argument for the institutionalization of appreciative approaches in extension programs. Such institutionalization would influence the negative discourse often directed toward the extension discipline. An Appreciative Inquiry approach offers an alternative, constructionist method to guide extension practitioners to envision a robust, positive future. Specific references are made to the perceptions of South Africans toward extension to anchor the pessimistic view. Public extension has been overly criticized in the agricultural development discipline for being irrelevant, nonfocused, and least beneficial to clients. Many blamed actors in extension for being complacent and incompetent. Yet, others perceived the challenging demands on extension as opportune for innovative reforms in strategy and approach. The paper argues that top-down approaches used in extension locate immense responsibility on practitioners to resolve development problems, thus limiting its chances for success. The resultant failure in approaches used is publicly perceived as failure of Extension.Three possible factors drive the pessimistic view. First, institutions of Extension tend to be narrowly perceived as useful to rural farm households. They overlook the heterogeneous character of communities, and their diverse survival strategies. Second, Extension approaches locate agenda-setting powers in the hands of the intervener, not the client. Last, extension interventions tend to be problem focused, often advancing problem modes of thinking. A shift in paradigm toward appreciative modes of probing, planning, and intervention for sustainable development is called for. This paper concludes with a pro-appreciative inquiry rationale for consideration by extension practitioners as they heed the call for Extension renewal.
\end{abstract}

Keywords: extension renewal, extension approaches, appreciative inquiry, new paradigm 


\section{Introduction}

Public extension has been overly criticized by policy-makers in the agricultural development discipline. The criticism has prevailed despite international and national efforts directed toward extension renewal. Extension practitioners, as visible faces in the disciplines, carried the brunt of the criticism and came to represent the negative face of public extension. What is the root cause of the extension critique and what informs the contrasting perspectives on its role?

Rivera (1990) predicted what he called, 'a turning point' for extension worldwide. In his view, the onset of the decade heralded, “...the end of the beginning because the great majority of public extension systems in developing countries ... have now arrived at a stage of consolidation or dissolution” (p. 4). Twenty years later, the discourse on the future role of extension continues with some seeing great value in extension reforms and consolidation, whilst others register concerns of failures in extension (FAO, 1999, 2000, 2001, 2005; FAO/World Bank, 2000; Swanson, 2008).

Such diverse perspectives, which suggest either a total collapse or resurgence of extension, gained prominence following the sector rationalization and critique directed at the World Bankfunded Training and Visit (T\&V) extension approach (Benor \& Harrison, 1977). Although others portrayed T\&V as the best model for effective extension management in Africa, some acknowledged its failure at implementation in rural Kenya (Anderson et al., 2006). The failure of T\&V destroyed the fragile image of public extension (World Bank, 1990; Rivera, 2008; Anderson et al., 2006). Since then public extension has, in some parts of the world, assumed the unflattering identity of a development discipline that is irrelevant, nonfocused, and least beneficial to clients (Leonard according to Rivera, 1990). And, pessimistic perceptions of extension have become a norm, rather than a novelty in development and academic discourse.

It is for this reason that practitioners in extension must begin to ask of themselves these hard questions. Is it conceivable that the consistent critique directed toward extension has turned into a 'self-fulfilled prophecy' among extension practitioners? Has the Extension discipline succumbed to the perpetual criticism, internalized the critique, and inadvertently lost confidence in and of itself? If so, can the same practitioners take it upon themselves to reverse the process and, thereby rebuild public confidence in the discipline?

Some might argue against the logic of internalization, given the dedication and commitment of most extension practitioners. Be that as it may, proponents of the latter view might consider apportioning blame for the pessimistic view to the methodologies and the approaches used in extension as failing the discipline. That being the case, is it possible that the intervention approaches currently used in extension programs locate much responsibility on extension to resolve development problems, hence the ongoing critique about extensions' failures? The correctness of the rationale to these questions is of no major relevance. Of importance is the acknowledgement by practitioners and their superiors of the urgent need for a positive rethink of extension toward the long-term survival of the profession.

Using the example of South Africa, the following section presents parallels between the dynamic socio-political contexts of the country and perceptions of negativism in Extension. In addition, evidence of the prevalence of public extension negativism in some parts of that country is presented. An overview and discussion of the relevance of Appreciative Inquiry (AI) in the transformational agenda for Extension follows. The next section presents a critique on the use of rigid top-down approaches in Extension, and the problem of confinement of public Extension to the rural farming communities. The paper concludes with a philosophical argument articulating the impact of the criticism on the discipline and its practitioners, and presents a rationale for constructive positive change. 


\section{Contributing Factors and Evidence of Negativism in the South African Public Extension}

This paper argues that the perception of negativism around public extension services is rooted, in part, to the socio-political and historical contexts of emerging democratic governments. The case of South Africa represents a good example of such. In that country, the contributions of extension to the broader national ideals of poverty alleviation, employment, political stability and food security are perceived as insignificant. South Africa gained independence in 1994, from apartheid rule. Under apartheid rule, all settlement patterns of the South African population, as well as their access to services was organised along racial lines. For instance, the country had 87 percent of her land designated as white settlements, with the remaining 13 percent assigned for settlement by the majority black population (Department of Agriculture, 1998). The legislated settlements for black people were designated as "homelands, or independent states," whilst those for whites were known as “white areas” (Kock, 1996). The long-term outcome of these skewed hegemonic polices was the perpetual association of inferiority and below par performance that carried the "homeland" identity.

Included in this quagmire were institutions of higher learning, agricultural training institutions, economic development programs, and support services that mirrored these white supremacy social patterns. It is therefore, not surprising that 16 years into democratic rule, government-led public extension services still carries the former homelands' burden of the inferiority identity.

Although shaped by this unique socio-political context, the dominant perception of public extension in South Africa follows global trends. Public confidence is weak around government-paid practitioners. And, studies have shown that in some parts of the country, a phenomenon known as 'support-the-visible' farmer prevails, where extension practitioners tend to service farmers along the roadsides, the service centres, and those that are independently progressive (Ngomane \& Mollel, 2000). As a result, few resource-poor farmers have direct access to public extension. Those who do have access, complain that extension practitioners experience difficulties responding to specific technical questions, and often provide inaccurate information (Machethe \& Mollel, 2000).

According to Kock (2006), the racial-based training programs for extension practitioners in South Africa have greatly compromised the profession. In a nutshell, graduates from the homelands received low quality training, and served only subsistence smallholder farmers. Competent University graduates supported the commercial farmers. The combination of these factors, namely, segregation policies and curriculum content weaknesses has contributed somewhat to the negative perception of public extension in South Africa. It is these factors that helped intensify the criticism against extension in the country, which permeated even the government policy-making process.

Government perceived the estimated annual budget allocation of USD \$50 million for public extension as a drain to the public coffers (Department of Agriculture, 1998). The situation prevailed despite reports that the majority of extension practitioners were highly demoralized, and in need of retraining opportunities (Machethe \& Mollel, 2000).

The long-term impact associated with the prolonged criticism of public Extension, particularly on its practitioners, remains unknown. Suffice to say that there is an urgent need to rethink the Extension service's intervention strategies and approaches, its role in development systems and partnerships, and its engagement patterns with beneficiaries. Extension service as a public good, may not afford a prolonged negative public image. For this reason, the paper introduces in the next section an approach worth consideration for possible extension renewal - the Appreciative Inquiry (AI) approach. 


\section{An Overview and Relevance of Appreciative Inquiry Approaches to the Change Discourse}

Appreciative Inquiry was developed by David Cooperrider and Suresh Srivastva at Case Western Reserve University in Cleveland in the 1980s (Cooperrider \& Srivasva, 1987; Ashford \& Patkar, 2001; Judy \& Hammond, 2006), as an innovative "strategy for positive change that identifies the best of 'what is' to pursue dreams and possibilities of 'what could be' " (Ashford \& Patkar, 2001, p. 4). The approach entails a wholly inclusive search for the collective strengths, drive, and the individual insight to pursue inspired, positive change. Central to the approach is a constructionist ethos that all individuals, organizations and communities carry within them the seed and desire for positive change. Evidence of this philosophical orientation is seen in its application. The Appreciative Inquiry approach help shift focus from the difficulties and the problems experienced by individuals, organisations and rural communities toward exploring opportunities and finding solutions. The aforementioned researchers reckon that though commonly applied in the corporate world, AI "has remained largely unknown to those working outside the corporate sector" (p. iv). The former had "widely praised AI for its effectiveness in helping corporations become more competitive by aligning their structures and activities with employee and client values” (p. iv).

Recent evidence show increasing interest and diversity in the application of AI for positive interventions in the development sector. For instance, development practitioners used AI to establish sustainable projects for rural communities in India (Asford \& Patkar, 2001). Others used AI to find pragmatic solutions to climate disruptions, biodiversity loss, and poverty (Myer \& Kent, 2008), while some found the approach useful in resolving institutional transformation conflicts in the area of education (Pinto \& Curran, 1998), promoting sustainable development of the desert communities in the Sahara (Elliot, 1999), and so forth. Irrespective of the context, an appreciative inquiry is commonly facilitated through four basic stages as follows.

\section{(a) Discovering periods of excellence and achievement}

Through interviews and story-telling, participants remember significant past achievements and periods of excellence. When was their organization or community functioning at its best? What happened to make those periods of excellence possible? By telling stories, people identify and analyze the unique factors - such as leadership, relationships, technologies, core processes, structures, values, learning processes, external relations, or planning methods - that contributed to peak experiences. (United Nations Development Programme, 2005, p. 11)

"Personal story questions would include examples such as 'Tell a story about a time when you felt you overcame a significant challenge to achieve something remarkable. How did you feel?' or 'Tell a story about a time when you really felt the support and encouragement of other group members?'” (p. 12).

\section{(b) Dreaming and envisioning an ideal organization or community}

In this step, people “...challenge themselves to imagine a future in which their group functions at its absolute peak...” (Ashford \& Patkar, 2001, p. 4). They derive strength from past achievements to envisage a desired future with tangible, achievable goals.

This aspect of appreciative inquiry is different from other vision-creating or planning methodologies because the images of the community's future that emerge are grounded in history and as such represent compelling possibilities. In this sense appreciative inquiry is both practical, in that it is based on the 'positive present,' and generative, in that it seeks to expand the potential of the organization or community. (United Nations Development Programme, 2005, p. 11) 
Through an envisioning exercise in India Ashford and Patkar (2001), recorded powerful statements made by communities on the path of their "awakening" such as "This community will plant 1,000 trees over the next two years to ensure the forest’s survival for future generations” (p. 20).

\section{(c) Designing new structures and processes}

In the design stage people form specific action plans to better harness their strengths toward achieving their desired future.

This stage is intended to be provocative- to develop, through consensus, concrete short- and long-term goals that will achieve the dream. Provocative propositions usually take the form of statements such as 'This community will do whatever is necessary to build a school and have a full primary cycle within the next year' or 'This village will protect what remains of the local forest and will plant one thousand trees over the next two seasons to ensure the forest's survival for future generations. Provocative propositions should stretch an organization or community, but they should also be achievable because they are based on past periods of excellence. (United Nations Development Programme, 2005, p. 12)

With much improved understanding and appreciation of their collective strengths, core values, and a common vision regarding their anticipated future, the people are then ready for the final stage, Delivery (Ashford \& Patkar, 2001).

\section{(d) Delivering the vision}

In this stage, people act on their provocative propositions, establishing roles and responsibilities, developing strategies, forging institutional linkages and mobilizing resources to achieve their dream. New project plans will be developed and initiated, new relationships will be established and the group will proceed with vision and a renewed sense of purpose. As a result of the appreciative process, people will have a better understanding of the relevance of new initiatives to the long-term vision of the organization or community. (United Nations Development Programme, 2005, p. 12)

The AI approach has been successfully used in both public and private settings where people were alienated, demoralized and demotivated, and proved to be a robust process for promoting positive change. According to Asford and Patkar (2001), its success has been confirmed with individuals, families, small and large groups. Although not a panacea for change, the use of appreciative inquiry can enable various actors in extension to create space for beneficiaries to build the foundation for change by beginning to address their own problems. The kind of negativism directed at public extension practitioners as discussed earlier requires some form of deliberate, positive action for redress. There has to be a targeted, purposeful change in the strategies and approaches used in Extension to address the alienation of practitioners from the discourse of success in the agricultural development discipline. Hence, the consistent argument for actors in the discipline to consider the use of Appreciative Inquiry, as an alternative approach for Extension program interventions.

The timing for such a step is ideal as evidenced by the increasing interest from international and national bodies in the great potential of innovative extension approaches for sustainable development. In embracing that growing interest, Extension may not fall back on the popular approaches responsible for its perceived "loss of face". Other factors notwithstanding, it is largely the failures associated with the top-down approaches advanced in Extension, which served as a magnet for prolonged criticism and mis-perception of the discipline as non-caring and incompetent. Linkage of the extension critique to the popular approaches used in extension, as well as its predominant confinement to subsistence agricultural development, is established next. 


\section{The Parallel between Top-down Approaches in Extension and Public Perceptions of Negativism}

Public extension has been criticized for its costly top-down approaches, such as the T\&V. Although some successes of a modified $\mathrm{T} \& \mathrm{~V}$ were registered elsewhere in Africa, some analysts believed that the approach failed. Training and Visit was found to be overly rigid in its principles of exclusivity to extension functions and inflexible in its adherence to time-bound programs, frequency of contact time, and excessive budget demands (Amezah \& Hesse, 2004; Leonard according to Rivera, 1990). Despite the widespread weaknesses of the approach, its proponents progressed on the seemingly misguided notion that qualified extension practitioners exist as passive conduits of research outputs and new technologies to the extension clients. Thus framed, the role of public extension practitioners was erroneously interpreted as that of a "postal service" good enough to pass on research information from subject matter specialists to farmers, and vice-versa without much interpretation. Even within the seemingly more integrated Farming Systems Research and Extension (FSR/E) approach (Swanson, 2008, p.17), questions related to the role of extension remained unanswered. Such as, should extension provide information for all within the FSR/E or should its focus be on extending technological information related to the agricultural aspects of the system?

A related disconcerting trend was that of a public extension service confined to the transfer of technologies in support of mostly rural smallholder farmers for subsistence purposes at the exclusion of rendering support for commercial farmer development. Moreover, the excessive focus of extension efforts on transferring technologies has overtime overlooked the human aspects and the social capital inherent in individuals, families and communities for societal advancement. Helping the individual, the group and the community identify and release their potential should be the central focus for Extension, and remains one of the strong points in appreciative inquiry. By exploring acts of excellence and achievement from the actors in development, the intervener creates awareness of the potential within the individual and/or group to do more.

\section{The Problem of Confinement of Public Extension to Rural Farming Communities}

According to the Food and Agricultural Organization (FAO) (2001) past development experiences and practice have confined the role of public extension generally within the agricultural development goals, with little emphasis placed on other areas of social development such as health and education. In both conceptualization and practice, at least in the African context, the institutions of Extension tend to be narrowly perceived as useful to rural-based agrarian households. In so going, Extension overlook the heterogeneous nature of developing communities and their diverse sustainable livelihood strategies. In public and private sector partnerships contexts, public extension is often portrayed as a conduit for transferring public good technologies for smallholder farmer development, whilst the transfer of proprietary technologies remain the role of the private sector.

Such limiting conceptualization and practice have prevailed despite growing evidence that farming households were heterogeneous in nature and often employed diverse livelihood strategies for their economic survival. Furthermore, the self-limiting framing of public Extension served as the basis for the advancement of top-down interventionist approaches, such as the T\&V and ToT. Thus framed, proponents of public extension for rural small farm households overlooked the growing reality that: (a) rural household family structures are undergoing rapid transformation as the economically active family members migrate to the urban centres in search of employment and better incomes (FAO, 2000); (b) the demand for urban agriculture and food security are increasing as urban populations grow (ibid); (c) rural farming communities engage in multiple livelihood activities outside the farming activity as survival strategies against natural disasters. Diverse livelihood strategies include handicrafts, temporary employment, microenterprises, and home-based teaching, which often require extension interventions; (d) the decision-making powers are shifting consistent 
with the shift in family headship. As economically active men move to the cities, more women assume the traditional male role as defunct head of the household for decision-making. As a result, extension messages designed for male-headed households might be interpreted differently by the defunct female headed households (ibid); (e) consultative leadership and governance is increasingly practiced in fledgling democracies in the developing world, and “...most communities in most parts of the world...have already seen a better future for themselves or their children. For good or ill, the revolution of rising expectations has already engulfed them” (Elliot, 1999, p. 282). As a result, in the agricultural development sector and related disciplines, the role of civil society and group decision making bodies such as producer associations is growing, calling for participatory transformational approaches in public Extension.

Grappling with these shifting trends, others have argued that extension as a function undergoing major transition, may now serve different purposes, such as "dissemination and collection of health information” (Rivera, 2008, p. 20), natural resource management, education, attitude change, human resource development, and related social services (Marsh \& Pannel, 1998; Swanson, 2008). Consequently, the term agricultural extension, which formerly referred to agrarian public sector extension, is being re-conceptualized to include all extension-type services provided by public, private and civil society organizations (Rivera, 2008, p. 20). In practice, the reconceptualization of extension is occurring at the opportune moment, and provides a basis for extension to broaden its scope in program design, envisioning, and implementation to include diverse client needs and aspirations. The next section seeks to establish a rationale for the complex phenomenon of association of public extension with the failure-syndrome.

\section{Making Meaning of the Criticisms: Failure Mirrored through Extension Practitioners}

The general misinterpretation and limiting perception of the role of public extension that was directly linked to the highly publicized T\&V approach within the sector (Ngomane, Thomson \& Radhakrishna, 2002), created fertile ground for framing "the beginning of the end" predictions for Extension. When T\&V failed, public extension portrayed the face of that failure. Extension practitioners, as the visible public face of the $\mathrm{T} \& \mathrm{~V}$ approach logically mirrored that failure. Thus, despite the involvement of other role players in the implementation of the approach, such as subject matter specialists and funding agencies, extension service became the most visible "object" for criticism and was characterized as a discipline on the verge of extinction. In the case of South Africa the "extension-going-extinct" discourse was advocated in the late 1990s at the highest level of government leadership. The negative discourse gave rise to hasty compliance-driven restructuring programs aimed at mainstreaming Extension with disciplines, such as agricultural economics, resource conservation, and so on.

The long-term impact of these compliance-driven restructuring efforts only began to unravel a decade later as poor clarity regarding the direction for extension. It continues to negatively influence the curriculum design strategies, delivery mechanism, and field implementation approaches.

In addition, by design and application Extension interventions are problem focused, often advancing problem modes of thinking at client level. Known successes of Extension in countries like Asia where the annual rate of return on extension investment were estimated at 79 percent (Alston et al., 1999) have thus far been unable to shake off the negative perception surrounding extension. In most agricultural development forums, a discussion on Extension is often negative, peppered with adjectives of failure. To date, the psychosocial and performance impact of these extended criticisms on Extension, and developing country extension practitioners in particular, is yet to be determined. A shift in paradigm - a new direction - toward advancing appreciative modes of thinking for sustainable development through public extension is crucial to save Extension from itself. 


\section{The Silver Lining: Opportunities for Public Extension Renewal}

In contrast to the dissolution discourse mentioned above, others are responding differently to the perceived lack of success of public extension, seeing it as an opportune era for re-organizing public extension. The Food and Agricultural Organization (FAO) led an intensive global program of work aimed at reviewing good agricultural extension and advisory services practices and proposed options for institutional reform. More market driven approaches, extension innovation systems, participatory rural appraisal approaches in their diversity are now adopted and practices in many countries (Swanson, 2008). There is a growing understanding within the sector of the broader role of extension in improving rural livelihoods and development of social capital for economic growth. Public extension focus is no longer interpreted as limited to improving household food security for the marginalized rural poor, but more on increasing incomes through high value commodity exports and rural employment (Swanson, 2006a; Swanson, 2008).

Although technology transfer remains an important function for improved yields there is sufficient sector consensus that this activity will become increasingly privatized as technologies become progressively more proprietary and as farmers become more commercialized (Swanson, 2006a). Likewise, the shrinking natural resource base due to the growing global population, climate change and economic growth serves as a catalyst for countries to urgently expand public extension systems and to allocate more resources and effort toward educating users on best "natural resource management” (ibid, p. xii) practices.

The role of extension in social capital development is progressively gaining clarity as more governments embrace the democratic rule of law (ibid). In most countries, public extension practitioners were barred from organizing farmers, women and youth groups for fear of the risk of militancy from these groups against the ruling government.

Following the lead of the Food and Agricultural Organization on the crucial role of extension in this regard, it should be noted that organizing rural youth groups was reported as an effective, long term strategy for building social capital for societal development. The public extension system in the United States thrives on this principle of massive organization of their youth groups through the 4-H and related youth organizations.

The adoption and use of participatory approaches in developing countries, especially within the Southern Africa Development Community (SADC) is beginning to encourage group social mobilization. However, there are limitations on participatory interventions in their current application, including Participatory Rural Appraisal (PRA), which entail the ease with which they locate agenda-setting-powers on the hands of the intervener, thereby compromising individual and community ownership of the process. In PRA interventions, the extension practitioner often becomes the custodian of the solution, thereby compromising the realization of social capital inherent within the community, and/or the household.

Another extension function that requires increasing attention has to do with the development of human capital, which includes increasing the technical and management skills of all types of households. Furthermore, development planners now place emphasis on differentiation amongst different types of farm households at micro and macro levels. These new emphasis on household differentiation brings to focus the differences among men, women, rural and urban youth, married and unmarried, educated and uneducated with respect to their skills base, the strength of their voice in development discourse, and decision making. Each category of people requires specific interventions that are unique to their group aspirations and capabilities. And when it comes to professional relevance to guide community members realize their human and social capital; extension is the frontrunner at the interface of public, private and civil society mobilization for positive societal transformation.

This paper argues that for public extension system to transform its image, to be more effective in improving rural livelihoods and better valued by the clientele, it should transform its focus, 
structure and approach starting with a redefined role for its practitioners. In addition, the extension practitioners should develop intrinsic pride and self-worth as they contribute toward the new constructionist direction for the discipline. With participatory people-focused approaches gaining legitimacy in the extension transformational agenda for sustainable rural livelihoods development, there exist a stronger need to harness and intensify such positive energy for change at intervention envisioning, action planning, and implementation levels. Envisioning and action planning are some of the core principles advocated in appreciative inquiries. In other contexts, such as in education and health, the Appreciative Inquiry philosophy was found to be one possible method capable of guiding extension practitioners envision a vital future through the challenging change landscape by identifying the "best of what is" and building on their individual, group, organizational and system strengths to explore the possibilities of "what could be."

\section{Constructing a Case for the Use of Appreciative Inquiry in Extension}

Extending knowledge effectively and efficiently from reputable knowledge sources to the endusers is a primary function for extension across disciplines. In a nutshell, success of the knowledge extended process relies largely on the receptivity of the end-users to change (new knowledge), the purposefulness and value of the product (intervention), and the technical confidence level of the change agent (extension practitioner), in disseminating, and interpreting the information.

Of late, the use of participatory rural approaches in extension, such as PRA, has gained popularity in sub-Saharan Africa, and other parts of the developing world. Participatory approaches are applied to help identify local problems, resource constraints, and unmet core needs for extension programs. Although the application of these approaches has gained popularity in some development aspects; they are not without limitations.

Lessons from the Canadian based International Institute for Sustainable Development (IISD) and the India-based non-government organization, MYRADA revealed the following weaknesses relative to the application of participatory approaches;

While these approaches encourage participation, emphasize the importance of local knowledge and address real problems ... such approaches often failed to sustain community participation. MYRADA concluded that deficit-based approaches left people with the impression that their community was full of problems and needs, most of which require the help of the outsiders to overcome. The focus on needs entrenched a sense of dependence that reduced people's motivation to initiate their own development activities. (Ashford \& Patkar, 2001, p. 5)

Pro-blematic experiences similar to the one described above necessitates the need for a paradigm shift from, or at least some adaptation, of deficit-based approaches in extension program development towards those that capitalize on local strengths, local achievements, and adequately engage the end-users in the pursuit of their aspirations. This paper contends that the extension discipline is not immune from deficit-based tendencies. Supporting this view is Peutz and Kroths' (2009), observation that "as a profession”, extension was "good at looking at problems and trying to improve” (p. 2). By applying appreciative strategies, extension practitioners could bring about purposeful and sustainable transformation, not only amongst them, but could enhance the human and social capital of the end-users for better livelihoods.

\section{Conclusion}

Public sector extension is highly essential for transformational interventions in both rural and urban communities. It is a funnel through which indigenous and scientific knowledge can be distilled for ease of appreciation by all end-users. It is an ideal professional presence for energizing diverse communities in their struggle against poverty and food insecurity. The discipline of extension remain 
one of the few disciplines in social sciences designed to help release human and social capital potential amongst its actors. It has become “...a 'frontrunner' in government efforts at public sector reform” (Rivera, 2008 citing Rivera, 1999), especially in the developing countries of sub-Saharan Africa (p.20).

This paper presented a critical opposing view to the historic association of extension with the discourse of failure. There is a need to review the framing of Extension as "knowledge extended," or "knowledge applied," and "knowledge transferred," in these changing times, as the common interpretation of such phrases limit the role of extension practitioners to that of extending research knowledge without much distillation. Recent work done by FAO and the World Bank (2000) regarding the strategic vision and guiding principles for agricultural knowledge systems suggest that much adaptation occurs in the research and extension knowledge system, with immense contribution from extension practitioners. Evidence of the shifting trends and new thrust for extension is growing, with numerous agencies calling for institutional reviews of extension functions, curriculum content, delivery approaches, and more focus on organizational mobilization of its clients in the market environment.

Putting effort toward a positivist shift in the direction of extension is especially important in that, the needs, demands, and aspirations of the actors in the system are shifting; getting more diverse, more complex, and integrated within the broader society and the economy (Ngomane, 2004). Extension dare not be complacent and linear in its approach. The same author argues that by assuming a linear, homogeneous approach to extension programming, the system downplays the porous boundaries, which define the myriad socio-cultural, economic, and political factors shaping our new society. Actors in Extension should strive to re-define their roles as educators, as facilitators, and as builders of community coalitions using as a reference point proven successes of traditional knowledge, local institutional resources, kinship tiers, and political will (Ngomane, 2004). The era for wallowing in professional deficit- mode has gone past, giving way to much needed space for nurturing the individual and communal strengths inherent in all Extension actors.

The use of new envisioning, action planning and implementation approaches for technology development and adoption, not only incorporates the collective knowledge of key role players, it increases the likelihood that research results shall be applied by giving the community space to realize its own collective strength (ibid). Appreciative Inquiry provides a framework for the realization of such strengths toward the development of sustainable livelihoods. As others have learned, “...by using questions to discover the strengths and successes that exist in every individual and community, a sense of hope is generated through which people begin to anticipate a better future” (Ashford \& Patkar, 2001, p. 4).

This paper end by re-iterating the urgent need for Extension to re-invent Itself to be more relevant to the contemporary demands of the $21^{\text {st }}$ century, and to counter the negativism associated with the discipline. The paper argued that the traditional approaches currently used in Extension have, so far not enabled its actors to advance the renewal agenda. That adopting the use of an Appreciative Inquiry approach shall enable all actors in Extension to gain a better understanding of their dynamic and multiple environments for better program development. The actors shall be energized to take on more challenges in a positive mindset. There is no better time than the present for public Extension to consider a positive shift in the current intervention paradigm from a deficitbased to an appreciative inquiry approach. 


\section{References}

Alston, J. M., Marra, M. C., Pardey, P. G., \& Wyatt, T. J. (1999). Research return redux: A metaanalysis of the returns to research and development. Washington, DC: International Food Policy Research Institute, EPTG Discussion Paper No. 38.

Amezah. K., \& Hesse. J. (2004). Ghana: Reform in the Ghanaians extension systems. In W. Rivera, \& G. Alex (Eds.), Decentralised systems: Case studies of international initiatives. (pp. 12-17). Washington, DC: International Food Policy Research Institute, ARD Discussion Paper No. 8.

Anderson, J. R., Feder, G., \& Ganguly, S. (2006). The rise and fall of Training and Visit extension: An Asian mini-drama with an African epilogue. In A. W. van den Ban \& R.K. Samanta (Eds.), Changing roles of agricultural extension in Asian nations (pp. 149-174). New Delhi: B.R. Publishing Corporation.

Ashford, G., \& Patkar, S. (2001). The Positive Path: Using Appreciative Inquiry in Rural Indian Communities. Canada: International Institute for Sustainable Development and MYRADA.

Benor, D \& Harrison, J. Q. (1977). Agricultural extension: The Training and Visit system. Washington, DC: The World Bank.

Cooperrider, D. L., \& Srivasva, S. (1987). Appreciative inquiry in organizational life. Research in Organizational Change and Development, 1, (pp. 129-169). Greenwich: CT. JAI Press.

Department of Agriculture. (1998). National Agriculture Policy in South Africa. Retrieved November 11, 2009, from http://www. nda.agric.za/doc/policy98.htm

Elliot, C. (1999). Locating the energy for change: An introduction to appreciative inquiry. Washington, DC: International Institute for Sustainable Development.

FAO. (1999). The farming systems development (FSD) approach to improved management of farm systems - An FSD handbook for the front-line extension worker. Rome: Food and Agricultural Organization, Agricultural Support Systems.

FAO. (2000). From farmer to planner \& back: Harvesting best practices. Rome: Food and Agricultural Organization, Women in Development Service

FAO. (2000). Global farming systems study: challenges and priorities to 2030 - synthesis and global overview. Rome: Food and Agricultural Organization, Rural Development Division.

FAO. (2000). Urban and peri-urban agriculture. Rome: Food and Agricultural Organization.

FAO. (2001). Agricultural and rural extension worldwide: Options for institutional reform in the developing countries. Rome: Food and Agricultural Organization, Rural Development Division.

FAO/World Bank. (2000). Agricultural knowledge and information systems for rural development: Strategic vision and guiding principles. Rome: Food and Agricultural Organization.

Judy, S., \& Hammond, S. (2006). Introduction to Appreciative Inquiry. Silva Forest Foundation. Retrieved May 13, 2009 from http:// www.silvafor.org/assets/silva/PDF/AppreciativeInquiry.pdf

Kock, B. H. (2006). A story of agricultural extension in South Africa. Pretoria: South African Society for Agricultural Extension.

Machethe, C. L., \& Mollel N. M. (2000). Extension and support services for smallholder agricultural development in South Africa: Who is the smallholder farmer? In B. Cousins, (ed.). At the crossroads: Land and agrarian reform in South Africa into the 21st century (pp. 340 - 348). Cape Town: University of the Western Cape, Land and Agrarian Studies. Retrieved May 4, 2009 from http://www.sarpn.org.za/documents/d0001320/P1563-Cousins_2005.pdf

Marsh, S. P., \& Pannel, D. J. (1998). Agricultural extension policy in Australia: The good, the bad, and the misguided. Australian Journal of Agricultural \& Resource Economics, 44(4), 605-627.

Myers, N., \& Kent, J. (2008). The citizen is willing, but society won't deliver: The problem of institutional roadblocks. Washington, DC: International Institute for Sustainable Development. 
Nagel, U. J. (2005). Back on the agenda: Extension and its institutional linkages - some personal experiences on the re-discovery of a key player. Berlin: Humboldt University.

Ngomane, T. (2004). The evolution of Extension processes and practices in relation to smallholder farming in Southern Africa. “New Directions for a Diverse Planet." Proceedings of the $4^{\text {th }}$ International Crop Science Congress. Brisbane, Australia. Retrieved April 16, 2010 from http://www.cropscience.org.au/icsc2004/symposia/4/1/1053_ngomanet.htm

Ngomane, T., \& Mollel, N. (2000). Transformation and restructuring needs for smallholder irrigation in the Northern Province of South Africa: Makuleke farmers’ perspective. Unpublished Master's Thesis. Petersburg: University of the North, South Africa.

Ngomane, T., Thomson, J., \& Radhakrishna, R. (2002). The public sector agricultural extension system in the northern province of South Africa: A system undergoing transformation. Journal of International Agricultural and Extension Education, 9(3), 31-37. Retrieved Aug 12, 2007 from http://www.aiaee.org/archive/Vol-9.3.pdf

Peutz, J., \& Kroth, M. (2009). Using appreciative inquiry to advance extension. Journal of Extension, 47(4) Article 4TOT1. Retrieved November 11, 2009 from http://www.joe.org/joe/2009august/tt1.php

Pinto, M., \& Curran, M. (1998) Laguna Beach Education Foundation, School power. In S. A. Hammond, \& Royal, C (Eds.). Lessons from the field: Applying appreciative inquiry. (pp. 16 47). Plano, TX: Practical Press Inc.

Rivera, W. M. (1990). Future of extension worldwide. Journal of Extension, 28(3) Article 3FUT1. Retrieved November 02, 2009 from http://www.joe.org/joe/1990fall/index.php.

Rivera, W. M. (1999). Global differences in the reform of agricultural extension worldwide: Confronting the new paradigm. Proceedings of the $15^{\text {th }}$ annual AIAEE Conference. Trinidad and Tobago.

Rivera, W. M. (2008). The 'business' of the public sector: Extension in transition and the balance of powers. Journal of International Agricultural \& Extension Education, 15(2), 19-30.

Swanson, B. E. (2006a). The changing role of agricultural extension in a global economy. Journal of International Agricultural and Extension Education, 13(3), 5-18.

Swanson, B. E. (2008). Global review of agricultural extension and advisory service practices. Rome: Food and Agricultural Organization.

United Nations Development Programme. (2005). Leadership through social artistry and Appreciative Inquiry. UNDP Local Government Programme. Retrieved May 23, 2010 from http://www.capacity.org/es/content/download/5445/91660/file/Leadership+Through+Social+Ar tistry+and+Appreciative+Inquiry.pdf

World Bank. (1990). Agricultural extension: The next step. Washington, DC: World Bank, Policy and Research Series No.13. 